\title{
Should action take priority over further research on public health?
}

We have evidence on which to act, and inaction costs lives, argue Simon Capewell and Paul Cairney. But Aileen Clarke says our understanding of the human behaviour that leads to unhealthy choices is still lacking

\section{Simon Capewell professor ${ }^{1}$, Paul Cairney professor ${ }^{2}$, Aileen Clarke professor of public health and health services research ${ }^{3}$}

'Public Health and Policy, Institute of Psychology Health and Society, University of Liverpool, Liverpool, UK; ${ }^{2}$ University of Stirling, Stirling, UK; ${ }^{3}$ Warwick Medical School, Warwick, UK; Correspondence to: S Capewell Capewell@liverpool.ac.uk, A Clarke Aileen.Clarke@warwick.ac.uk

\section{Yes-Simon Capewell, Paul Cairney}

Centuries of improvements in public health reflect actions not excuses. There are important reasons to act now, rather than wait for perfect evidence.

Firstly, we know what causes most avoidable disease and deaths: poverty, poor diet, tobacco, and alcohol. ${ }^{1}$ And we know which evidence based interventions work. Therefore, to wait for yet more evidence is ethically unacceptable. Further delay will perpetuate the current huge and unequal burden of harm. Policy makers and clinicians need to act now, on a "balance of probabilities," not wait for a mythical evidence "magic bullet" to remove all doubt.

\section{Politics, evidence, and ambiguity}

A focus on "insufficient evidence" often betrays a simplistic view of policy making, that evidence is used merely to reduce uncertainty. Politics is actually about using evidence to reduce ambiguity. Evidence is important, but policy change requires a powerful story and the ability to exploit windows of opportunity. ${ }^{2}$ Effective political actors use evidence to draw attention to urgent problems, encourage policy makers to understand them primarily as epidemics, and generate demand for evidence based public health solutions-for example, the recent smoke-free legislation and levy on sugary drinks.

A delayed response to evidence can be damaging. For example, a cumulative meta-analysis published in 1972 provided ample evidence that thrombolysis reduced deaths from heart attack by about $25 \%{ }^{3}$ However, repeated failure to consider this substantial evidence, compounded by medical conservatism, meant that thrombolysis was not widely used until 20 years later. Many patients were thus denied effective treatment, ${ }^{4}$ likely resulting in about 50000 avoidable deaths over two decades in the United States. Systematic reviews alone may not be sufficient to change practice; evidence based guidelines need to be developed and, crucially, implemented.

When scientists refer to "insufficient evidence" they may naively help opponents of policy change, including vested interests.
Corporations producing harmful commodities such as tobacco, alcohol, junk food, or sugary drinks routinely oppose regulation or taxation because they reduce profits. These merchants of doubt use MARSH "denialism" tactics ${ }^{56}$ to oppose public health. MARSH stands for misinformation; attack of evidence, scientists, and public health advocates; recruiting stooges; substituting weak policies; and heaping money on politicians.

Without strong public health advocacy, these tactics can be profoundly effective. For example, tobacco use contributes to over six million premature deaths a year worldwide. However, the global experience of tobacco policy suggests that industry denial tactics can deflect effective regulation and thus allow decades of delay between the identification of solid evidence and a proportionate policy response. ${ }^{8}$

\section{Learning from previous triumphs}

We can learn useful lessons from previous public health triumphs. All were predicated on action, not excuses to await more evidence. Mackenzie recently summarised a century of public health successes (including safe drinking water, sanitation, immunisation, road safety and seat belts, tobacco control, and pollution regulation). ${ }^{9}$ Each was built on a foundation of scientific research. However, that evidence was but the first step on the SUPPORT pathway of cumulative policy change. SUPPORT stands for: scientific evidence emerges; understanding spreads; professionals accept the model; public and politicians become aware and then supportive; opposition from vested interests is slowly overcome; regulation is introduced; taxation is often used to reinforce regulations (as in tobacco and alcohol control).?

Does responsibility for tackling known causes of preventable disease lie mainly with individuals? No. ${ }^{10}$ We therefore suggest that our over-riding ethical duty is to use evidence to maximise current and future health for our patients, families, and communities. Health professionals must therefore also ensure that evidence based interventions are piloted and evaluated 
before widespread use, closely monitor their implementation and outcomes, and modify as necessary.

In conclusion, we have a duty of care to our fellow humans to accelerate policy reform through advocacy, not wait naively for the evidence to "speak for itself." The prize is a regulatory framework that promotes a healthy environment, supports healthy behaviour, and maintains clean drinking water, clean air, and safe cars and buildings..$^{10}$ These urgent rules of evidence in action are thus very different to the "wait and see" rules of endless evidence production.

The huge current burden of avoidable disease is a scandal. "Insufficient evidence" is an excuse for dither and deaths. We already have enough evidence to support public health; what we need now is more action from policy makers, managers, and clinicians.

\section{No-Aileen Clarke}

Proponents for action are clear about the changes needed to improve public health: we need to eat less, consume less sugar, and take more exercise. The effects of obesity, poor diet, lack of physical activity, and overconsumption of alcohol and fizzy sugary drinks are plain, they say. The research needed to improve public health is done and dusted, and all we need to do is get on with things. Yet a central question remains. If the causes of ill health are clear and all that is required is for us to take action, why hasn't this happened?

Research shapes our understanding of health and wellbeing. Research informs policy, and policy interprets and informs research. Research is key to understanding how individuals and organisations, governments, and industries behave. Research is vital to interpret the likely effects of changes in our attitudes, cultures, and societies, as well as in our politics, economics, and ultimately in our health and wellbeing.

\section{Understanding healthier choices}

Clearly, there is still research to do. How do we continue to improve the health generating environment so that people can make the best choices to become healthier? And more research is needed to understand how a person can make long term choices to sustain and improve health, through his or her life.

Public health research has tended to focus on the epidemiology and causes of diseases such as heart disease, cancer, and stroke. But insufficient attention has been paid to interventions that target the underlying causes of reduced wellbeing and disability. We know so much about the distribution and causes of obesity and diabetes, for example, but not enough about what to do about them.

We know that a waist circumference greater than $90 \mathrm{~cm}$ for men and $83 \mathrm{~cm}$ for women should prompt action, because of altered blood glucose metabolism and subsequent diabetes. ${ }^{11}$ However, we do not yet have a reliable mechanism (apart from expensive surgery) to help people maintain and limit their weight that really works on a long term basis.

Meanwhile, $38 \%$ of US adults have prediabetes and $33 \%$ of older US adults have diabetes. ${ }^{12}$ And just under $10 \%$ of UK children at age 4-5 years arrive at school already obese. ${ }^{13}$ Why do the couch, the television, and the car sometimes appeal more than the park, the gym, and the bicycle? For our future health and wellbeing, we desperately need research to help us understand our behaviour better. ${ }^{14}$ We know precisely how much salt leads to what increase in blood pressure, ${ }^{15}$ with what cardiovascular risk, ${ }^{16}$ but we still don't really know why our taste for salt, sugar, and fat is so persistent.
Last year Public Health England reported that despite widespread publicity on the benefits of exercise, six million adults in England do not take even a single 10 minute walk a month. ${ }^{18}$ More worryingly, the increase in life expectancy in the UK has slowed, and women are now spending more years in poor health. ${ }^{19}$ We need a new approach to research to improve public health, a personal and social approach that does not just log declines in population indicators but which considers us as individuals who make choices within our social contexts.

\section{Socially robust knowledge}

Nowotny suggests that research needs to acknowledge "social, economic, cultural and political factors." ${ }^{20}$ Such "socially robust knowledge" gets under our skin, helping us to understand how we tick. Scientific knowledge needs to be produced that can speak to us as ordinary people. Kelly and Russo, for example, describe refocusing research about preventing alcohol misuse from the aetiological to the practical. ${ }^{21}$ Understanding "social practices" and "settings and contexts" are key, they argue.

However, behaviour change sciences are still young and relatively underfunded. In its report on behaviour change, the House of Lords science and technology select committee concluded that much is understood about human behaviour but there is "relatively little evidence on how to change the behaviour of populations." 22

Clearly we need more research in public health. Research is needed now to interpret current knowledge and to develop socially robust and practical ways to change and sustain our individual behaviour, to improve our individual health, and thus to improve the public health of our patients, families, and communities.

Provenance and peer review: Commissioned; not externally peer reviewed.

Competing interests: All authors have read and understood BMJ policy on declaration of interests and have no relevant interests to declare. AC is partly supported by the NIHR CLAHRC West Midlands initiative. The views expressed here are those of the authors and not necessarily those of the NHS, the National Institute for Health Research, or the Department of Health.

Provenance and peer review: Commissioned; not externally peer reviewed.

1 Newton JN, Briggs ADM, Murray CJL. Changes in health in England, with analysis by English regions and areas of deprivation, 1990-2013: a systematic analysis for the Global Burden of Disease Study 2013. Lancet 2015;386:2257-74.

doi:10.1016/S0140-6736(15)00195-626382241

2 Cairney P, Oliver K, Wellstead A. To bridge the divide between evidence and policy: reduce ambiguity as much as uncertainty. Public Adm Rev

2016;76:399-402doi:10.1111/puar.12555.

3 Lau J, Antman EM, Jimenez-Silva J, Kupelnick B, Mosteller F, Chalmers TC. Cumulative meta-analysis of therapeutic trials for myocardial infarction. N Engl J Med 1992;327:248-54. doi:10.1056/NEJM1992072332704061614465

4 Ford ES, Ajani UA, Croft JB. Explaining the decrease in US deaths from coronary disease, 1980-2000. N Engl J Med 2007;356:2388-98. doi:10.1056/NEJMsa05393517554120

5 Oreskes N, Conway EM. Merchants of doubt: how a handful of scientists obscured the truth on issues from tobacco smoke to global warming. OCLC, 2010.

6 Chan M. 2013. WHO director-general opening address at the 8th global conference on health promotion. Helsinki, Finland, 10 June 2013. http://www.who.int/dg/speeches/2013/ health_promotion_20130610/en/

7 Capewell S, Lloyd Williams F. The role of the food industry in health: lessons from tobacco? Br Med Bull 2018 (forthcoming).

8 Cairney P, Studlar D, Mamudu H. Global tobacco control. Palgrave, 2012doi:10.1057/9780230361249.

9 Mackenzie G. A public health century \#APHCentury. https://storify.com/gmacscotland/apublic-health-century-aphcentury-full-version

10 Capewell S, Lilford R. Are nanny states healthier states?BMJ 2016;355:i6341. doi:10.1136/bmj.634127927622

11 Friedl KE. Waist circumference threshold values for type 2 diabetes risk. J Diabetes Sci Technol 2009;3:761-9. doi:10.1177/19322968090030042420144326

12 Menke A, Casagrande S, Geiss L, Cowie CC. Prevalence of and trends in diabetes among adults in the United States, 1988-2012. JAMA 2015;314:1021-9. doi:10.1001/jama.2015.1002926348752 
13 National Statistics. National child measurement programme England, 2016/17 school year. ONS, 2017. https://digital.nhs.uk/catalogue/PUB30113

14 Marteau T, Dieppe P, Foy R, Kinmonth AL, Schneiderman N. Behavioural medicine: changing our behaviour. BMJ 2006;332:437-8. doi:10.1136/bmj.332.7539.43716497737

$15 \mathrm{He}$ FJ, Li J, Macgregor GA. Effect of longer term modest salt reduction on blood pressure: Cochrane systematic review and meta-analysis of randomised trials. BMJ 2013;346:f1325. doi:10.1136/bmj.f1325.23558162

16 Lewington S, Clarke R, Oizibash N, Peto R, Collins RProspective Studies Collaboration. Age-specific relevance of usual blood pressure to vascular mortality: a meta-analysis of individual data for one million adults in 61 prospective studies. Lancet 2002;360:1903-13. doi:10.1016/S0140-6736(02)11911-812493255

17 Cook NR, Cutler JA, Obarzanek E. Long term effects of dietary sodium reduction on cardiovascular disease outcomes: observational follow-up of the trials of hypertension prevention (TOHP). BMJ 2007;334:885-8. doi:10.1136/bmj.39147.604896.5517449506
18 Public Health England. 10 minutes brisk walking each day in mid-life for health benefits and towards achieving physical activity recommendations. Evidence summary. PHE, 2017. Gateway No: 2017294.

19 Public Health England, Health profile for England. Chapter 1: life expectancy and healthy life expectancy. PHE, 2017.Gateway No 2017051.

20 Nowotny H. Dilemma of expertise: democratising expertise and socially robust knowledge. Sci Public Policy 2003;30:151-6doi:10.3152/147154303781780461.

21 Kelly MP, Russo F. Causal narratives in public health: the difference between mechanisms of aetiology and mechanisms of prevention in non-communicable diseases. Sociol Health IIIn 2018;40:82-99. doi:10.1111/1467-9566.12621.29023919

22 House of Lords Science and Technology Select Committee. Behaviour change. 2011. https://www.publications.parliament.uk/pa/ld201012//dselect/ldsctech/179/179.pdf

Published by the BMJ Publishing Group Limited. For permission to use (where not already granted under a licence) please go to http://group.bmj.com/group/rights-licensing/ permissions 